\title{
Adding Value to the Teaching and Learning of Design and Technology
}

\section{Ian S. Ginns, Stephen J. Norton, and Campbell J. McRobbie. Queensland University of Technology, Australia}

Email: i.ginns@qut.edu.au

\begin{abstract}
It has been argued that design and technology can be used as a vehicle for teaching science and vice versa. In this paper, we report an investigation into Grade 6 students' understandings of concepts embodied in the Systems strand of a technology syllabus as they grappled with a unit of work in technology for the first time. The unit of work involved students in the design and construction of simple systems, followed by experiences with more complex systems. Qualitative research methods were used to investigate the activities of the students as they engaged in the design and technology learning experiences for eight weeks. Data sources included student and teacher interviews, video and audio recordings of whole class and small group interactions, students' notes, drawings and diagrams, and researchers' field notes and reflections. Changes in students' ability to identify the individual components and analyse how the components worked together in systems, and evidence of students' use of scientific understandings for explanations, were noted as the unit of work progressed. An improvement was observed in students' abilities to describe relationships between inputs, processes and outputs, and outline sequences of cause and effect. Recommendations are proposed for enhancing the value of both design and technology and science if both subjects are taught together as part of an integrated program in primary schools.
\end{abstract}

Key words: Technology: systems

\section{Introduction}

The American Association for the Advancement of Science (AAAS; 1993), through Project 2061, emphasised the value of technology by actively promoting its inclusion in the school curriculum in order to ensure that students are informed about its nature, applications, and ramifications. Policy and syllabus documents in other countries (e.g., Curriculum Corporation,1994; DES/Wales, 1990) similarly emphasise the importance of studying technology.

A major thrust of Project 2061 (AAAS, 1993) was the intention that technology should be seen as a vehicle for learning science. Technology and science have much in common, thus it is not surprising that the two curriculum areas should be examined for commonalities and potential for integrated teaching and learning experiences. For example, they share the production and transformation of representations and actionorientation language, and technology related activities provide a rich platform for learning science when they focus on designing and testing artefacts, and critical analysis in explaining successful or unsuccessful performance of the artifacts (Roth, 2001).

\section{The Study}

The concept of systems presents the possibility of establishing extensive overlap between technology and science for teaching purposes. Indeed, Chen and Stroup (1993) proposed that general systems theory could be used as a framework to unify science and technology education, arguing that several dimensions of systems theory make this unification possible. The dimensions are: a system-interacting parts operating as a whole; change - transformation with time as a referent for change and dynamics; feedback - provides mediation between the goal and system behaviour; and interactions - the input and output of matter, information and energy. These dimensions are evident in the definition of systems provided in the Technology Syllabus (Queensland Schools Curriculum Council, 2002, p. 16), "Systems are comprised of interactive components and have inputs, processes and outputs that can be controlled in logical ways based on certain principles." The dimensions also provide an interpretive framework, compatible with syllabus 


\section{PATT 13}

documents, which can be used to make judgments about a student's ability to identify system components and the interactions between the components and systemic behaviours.

An investigation into Grade 6 students' understandings of concepts embodied in a technology unit of work based on the Systems strand of the Queensland technology syllabus is reported. The paper examines the technology unit for students' learning outcomes in both technology and science.

\section{Methods and techniques}

An interpretive research methodology (Erickson, 1998) was utilised in order to understand the meanings and purposes that the participants attached to their activities (Lincoln \& Guba, 2000). Trustworthiness, authenticity and the benefits of the hermeneutic process were the benchmarks for quality interpretive inquiry. Multiple data sources maximised the probability that assertions were valid.

\section{Participants}

The participants in the study were thirty Grade 6 students who attended a large, Brisbane primary school. All names used in the paper are pseudonyms. The class was engaged in a technology unit consisting of meaningful learning experiences of approximately 2 hours duration each week for eight weeks, prepared and implemented by the teacher in consultation with the researchers. The students worked in groups of three during the unit. Neither the teacher nor the students had experience with the technology curriculum previously. At the beginning of the year, the students had completed a science unit on mechanical energy, its forms and transformations.

\section{The technology unit}

A platform for students' learning was established by providing guided learning experiences for the first four weeks, which enabled the students to explore a number of simple systems, for example, bottle diver; telephone system; gears; pulleys; and sub-systems on a bicycle. The remaining four weeks involved students working on the construction of two robots using materials from the Lego Mindstorms - Dark Side Developer Kit. The robots included a battery powered motor, light sensor and simple feedback response programs. These components were incorporated in a single Lego block around which the rest of the robot was constructed. A moving robot could be pre-programmed to stop, stop and pause before continuing, stop and reverse, in response to a light stimulus.

The students constructed the first robot using a plan provided in the kit. They were encouraged to incorporate their own ideas in the design and construction of the second robot. Essentially, the unit provided the Grade 6 students with beginning experiences in technology, which could be used as a basis for subsequent activity for developing their own specifications for the construction of a system.

\section{Data sources}

All students were interviewed in groups of three in order to determine their prior understandings of concepts embodied in systems. Each participant was asked to identify the components of a hand cranked model generator and describe how those components interacted together to produce light.

Six focus students, representing a range of understandings of systems evident from the initial interviews, were selected for in-depth study using video and audiotaping techniques. The purpose of the in-depth component of the study was to observe the actions and discourse of these students as they worked together, interacted with other students, and the teacher.

Other data sources included (a) observations of classroom activity, and (b) each student's log book, which included, for example, drawings, and descriptions and results of tests on constructed artefacts. All students were interviewed, in their respective groups, for a second time at the completion of the technology unit to assess their understandings of systems, in particular, related to the robots that they had constructed. Salient portions from the interviews, videotapes and audiotapes, containing evidence of students' use, or development of concepts embodied in feedback systems, were transcribed and analysed using the interpretive framework (Chen \& Stroup, 1993). For example, were students able to identify system components, feedback mechanisms, and interactions (input; output)? 


\section{PATT 13}

The original intention of the unit was to focus on technology only, however, evidence accumulated during the study that students appeared to draw upon their existing understandings of science concepts when discussing and explaining their ideas. Hence, the nature of explanations was also examined for applications of scientific content.

\section{Findings}

For the purposes of this paper, the findings for one focus group only (Alice, Kate and Suellen) are presented in two sections - technology learning outcomes, and science learning outcomes.

\section{Technology outcomes.}

In the initial interviews, the three focus students provided responses of varying levels of complexity as shown below. Alice identified and described most of the components of the hand-cranked generator compared to Suellen and Kate who provided limited descriptions.

"The crank, there is wire, there is a light, it sort of switches, the crank. This is a magnet and that is copper wire. Well, when the crank is turning around it is generating energy from the magnet, and that is transposed into this thing (the coil), that flows up through there and into the screws and into the light bulb, which makes it light up." (Alice)

"It is a spinny thing with wires in it, with the wires wrapped around something (coil) and $\mathrm{N}$ and $\mathrm{S}$ (unsure what $\mathrm{N}$ and $\mathrm{S}$ were). They rub together kind of." (Suellen)

"You move that around (points to the crank). You twist it around and it goes down that (points to the wire) and that would probably go underneath and power the light, it shoots down the wire." (Kate)

Each student was able to identify the input, that is, turning the crank caused the attached wheel to spin. Suellen was uncertain about the output ("It's like not doing anything"), whereas Alice and Kate suggested that the output was light and electricity respectively.

During the technology unit, one particular aspect the focus students grappled with was the addition of propulsion systems to the robots. In the first robot, the motor turned a drive shaft connected via an arrangement of axles and cogs to wheels. The students were able to describe the system components and how the components interacted to propel the robot. For the second robot, they decided to construct legs for movement that could be operated by the addition of cams to the configuration of axles and cogs. Conceptualising the orientation of the cams in the propulsion system of the latter robot presented a problem for the group, which involved them in testing several different designs for the legs. They eventually succeeded in making the robot walk by "Turning these (the cams) in the opposite direction," (Alice). The students also tested and evaluated the effect of the light stimulus on the movement of the robot.

In the second interview, the focus group was able to identify several systems present in their robots, and was also able to identify inputs and outputs. For example, Kate noted, "When you try and make it do things, sometimes you flash a light on it and there must be a system that senses the light." They all recognised that the light stimulus was the input resulting in the movement of the robot. Alice drew attention to the general walking system in the second robot by stating, "The battery turns the little motor," and movement occurs. Suellen recognised that the output, in the form of motion, was also linked to the configuration of cogs in the propulsion system. These findings are indicative of an important advancement in the students' abilities to identify the interacting parts operating as a whole, feedback behaviour, and change.

\section{Science outcomes:}

The technology activities could be described as being bound up in what Roth (2001, p. 769) described the "seamless web" of technology and science. In the initial interview, there were already indications the students were drawing upon existing scientific understandings that may have been founded on the science unit completed earlier in the year. For example, Kate had conjectured that the output from the generator was electricity, "Because the light went on." Although, unable to identify initially the output from the generator, Suellen built on Kate's assertion by suggesting that spinning the crank faster meant that, "It's 


\section{PATT 13}

sort of building up electricity." Alice provided a detailed description of possible energy changes as shown in the technology outcomes section.

On completion of the unit, the focus students were able to identify energy forms of relevance to the robots (e.g. light energy), outline how gears of different sizes and axles interacted to produce the movement of the robots, and outline cause and effect relationships. For example, they recognised that the motor, when operating, turned a large cog ("The motor turns that cog there," - Alice pointed to the large cog). The large cog, in turn, caused several smaller cogs (two at right angles to each other) to rotate and turn the wheels of the first robot, or operated the cams for the walking robot. The concept of gear ratio was evident in their observations that the small cogs rotated faster than the large cog, and they rotated in opposite directions. The students also described the effect of friction when comparing the movement of the robot with wheels and the walking robot.

\section{Discussion and Conclusions}

It may be concluded that Suellen and Kate's initial, limited understandings of systems changed to more coherent understandings as an outcome from engagement in the technology unit. All three students were able to identify components of systems, explain interactions of the components, and speculate on inputs and outputs, and how feedback systems might work. Most students' explanations for how their artefacts worked displayed evidence of the use of the concepts and language of science indicating that they were drawing on prior, or new, understandings of science acquired through designing, constructing and testing artefacts. Hence, there were important learning outcomes for both technology and science for the focus students.

We suggest that the focus students' learning was enriched because they drew upon their understandings of science to provide more meaningful explanations and observations when probed, for example, about the construction of the robots, and the role of light sensor in varying the motion of the robot. The students constructed links without scaffolding by the teacher. Teachers should build upon students' ability to make links between technology and science, in particular, to use science to explain important features of the created technology. Therefore, it is recommended that teachers engage students in class discussion to explore and elaborate upon explicit technology and science understandings being investigated at important points in a unit of work. For this to be effective, students may have to be working on similar tasks or the same task. Teacher educators must assist primary teachers with the identification of relevant technology and science concepts embedded in a technology task and where class discussions of the kind described above would be most effective. We must help teachers to capitalise on opportunities to enhance the value of both technology and science if both areas are taught together in an integrated program.

\section{References}

American Association for the Advancement of Science (AAAS). (1993). Science for all Americans: Project 2061. New York, NY: Oxford University Press.

Chen, D., \& Stroup, W. (1993). General systems theory: Toward a conceptual framework for science and technology education for all. Journal of Science Education and Technology, 2(3), 447-459.

Curriculum Corporation. (1994). A statement on technology for Australian schools. Carlton, Victoria: Curriculum Corporation.

DES/Wales. (1990). Technology in the National Curriculum. London: HMSO.

Erickson, F. (1998). Qualitative research methods for science education. In B. J. Fraser, \& K. G Tobin (Eds.), International handbook of science education (Part 2, pp. 1155-1173). Dordrecht, Netherlands: Kluwer Academic Publishing.

Lincoln, Y. S., \& Guba, E. G. (2000). Paradigmatic controversies, contradictions, and emerging confluences. In N. K. Denzin \& Y. S. Lincoln (Eds.), Handbook of qualitative research (2nd ed., pp. 163188). Thousand Oaks, CA: Sage.

Queensland Schools Curriculum Council. (2002). Science: Years 1 to 10 Syllabus. Brisbane, Queensland: Queensland Schools Curriculum Council.

Roth, W-M. (2001). Learning science through technological design. Journal of Research in Science Teaching, 38(7), 768-790. 